\begin{tabular}{|c|c|c|}
\hline $\begin{array}{c}\text { Editorial \& Publishing Offices : } \\
\text { MACMILLAN \& Co., LTD. } \\
\text { ST. MARTIN's STREET } \\
\text { LONDON, W.C.2 }\end{array}$ & & $\begin{array}{l}\text { Telegraphic Address : } \\
\text { Phusis, Lespuare, LoNDoN } \\
\text { Telephone Number : } \\
\text { WhITEHALL } 88_{31}\end{array}$ \\
\hline Vol. I43 & SATURDAY, APRIL 22, I939 & No. 3625 \\
\hline
\end{tabular}

\title{
Research in Africa
}

$\mathrm{I}^{\mathrm{N}}$ June next the generous grants of the Rockefeller Foundation to the International Institute of African Languages and Cultures for the promotion of linguistic and anthropological research in Africa will cease ; and the Council of the Institute, it is stated in its annual report for 1938 (Africa, 12, 1; 1939), being fully aware of the urgent need not merely of continuing, but also of extending and strengthening this work in every way, now has under consideration its arrangements for the future. These must necessarily depend upon the funds available; but the wide interests implicated in the vast field to be covered, and the gravity of the issues to which the researches of the Institute contribute understanding, should ensure that financial considerations will not be allowed to cramp its work.

Since 1931, when the scheme of research which is now nearing its final stages was first formulated by the Institute, sixteen full-time research fellowships have been awarded. Of the holders of these, three are still in the field, completing their investigations in Uganda, Nyasaland and Bechuanaland respectively. The remainder, having finished their field work, either have reported or are completing the preparation of their material for publication. These investigators have covered a wide field and have recorded observations of the culture of markedly diverse peoples. Research among African peoples has so vast a range that it may be said that even this organized scheme of investigation has done little more than pass beyond the fringe. Nevertheless, substantial progress has been made. Cultural records have been made among peoples in such widely distributed areas as the Anglo-Egyptian Sudan, Algeria, the Gold
Coast, Sierra Leone and Nigeria, Uganda, Kenya, Tanganyika, Nyasaland, Rhodesia, the Transvaal and South Africa.

Further to, and arising out of, these activities in research, discussion among the research fellows and other experts has led to the preparation by the Institute of a symposium on African political organization. This will be edited by Dr. M. Forres, research fellow, and Dr. E. E. Evans-Pritchard.

Obviously discussion of political organization raises many questions with wide ramifications in their bearing on the future of the African. For some time there have been indications here and there of a certain mistrust among the native populations-confined in the main, no doubt, to the more advanced and sophisticated-of both scientific investigation of native institutions and of the relation of indirect rule to such research. It has been alleged, with no small show of confidence, that the aim herein of the white man is "to keep the native in his place"- to stereotype his institutions and to fix his status once for all. If as the result of any discussion or research it should be possible to indicate the lines of a progressive policy of institutional development, adaptable to changing conditions of the day, while avoiding disintegration, it would placate discontent by eliminating ambiguities in the present position.

The linguistic side of research, which has always been a major interest of the Institute, has not been neglected. At the moment, two important works dealing with African languages are in the press; one on the languages of the Sudan by Dr. A. N. Tucker, based partly on material collected on an expedition financed jointly by the Institute and the School of Oriental Studies of the 
University of London, and one on the phonetic structure of the Kikuyu language by the late Miss L. E. Armstrong; while three other linguistic studies are either ready in manuscript form or are in course of preparation.

A further significant development of the Institute's research work, of wider scope than its application to the African field, is concerned with the nutrition of backward peoples-one of the most important subjects to which the attention of research fellows has been directed, if the trend of recent investigation is to be accepted in all its implications. Not only has this matter been under observation by Dr. Audrey Richards among the Bemba of Northern Rhodesia and is now being examined by Dr. Margaret Read among the peoples of Nyasaland; but also the plans for a nutritional field survey, which were drawn up by the Institute with a view to the needs of Africa, have been adopted, with revision and expansion, by an organization set up under the ægis of the Medical Research Council, of which the purpose is the co-ordination of nutritional research work throughout the British Colonial Empire. The nutritional investigation which Dr. Read is carrying out in Nyasaland now forms part of this scheme, which is being conducted under the direction of Dr. B. S. Platt, senior member of the staff for the co-ordination of the research. An ecological survey of Nyasaland is being carried out, in conjunction with the work on nutrition, by an agricultural officer, assisted by forestry and veterinary experts where necessary, the anthropological and sociological side of the investigation being entrusted to Dr. Read. As this is the first survey of the kind under the new organization, it is of particular importance for the development of technique, with a view to future research; while it is of no less notable significance that the socio-anthropological side of this very important question receives due recognition. The Government of Nyasaland has shown that it is fully alive to the value of the inquiry, and has granted every facility to the members of the expedition for their work.

Research such as is too briefly outlined above cannot be financed on a parsimonious scale; and the more closely the problems of Africa are scrutinized, the more evident does it become that future research must be extended to the limits of capacity in resources and personnel. When the results achieved by those who have worked in Africa during the last five or six years on behalf of the Institute of African Languages and Cultures are more fully available, confidence in its competence to continue to direct this work will be more than doubly assured. Further, the methods of investigation which have been followed by many, if not all, of its research fellows have been such that their results not only have conduced notably to the advancement of scientific knowledge, but they are also readily adaptable to the needs of administration, or other provinces of practical affairs. Nor have they failed on occasion to probe weak points in administrative methods, even under indirect rule, where a failure in the understanding, which the anthropologist alone could discern, has led to misinterpretation of custom, mistrust and even friction.

It is further to be noted that both the administration of the Institute's scheme of research and the selection of research fellows have had a marked effect in promoting that international co-operation which, in the eyes of those most competent to judge, is one of the essentials in the future guidance of development in Africa along right lines.

Meanwhile, a word of warning may not be out of place. The interest of African problems at the moment is so insistent, and at the same time so widespread, that there is a very real danger of a dissipation and waste of energy and resources, which could, and should, be concentrated in a single direction of effort to African research. The number of appeals for funds for purposes of research of widely varied character is growing apace, as is the number of organizations, some already in existence, others projected, on behalf of which these appeals are being made. As each one comes forward, it might indeed be considered to strengthen the argument for centralization and the concentration of effort in a single African institute, of which the purpose would be to co-ordinate and direct inquiry, as well as to pool information, and thereby the better to direct suggestion for the application of the results of research to practical ends, while at the same time advancing scientific studies. Not the least of the advantages of such an institute would be the greater weight it would carry, when urging upon authority that the benefits accruing to administration from the results of its researches, and more especially of such anthropological investigations as have been carried out by the Institute of African Languages and Cultures, were of a nature to merit a liberal subvention from public funds, as a return for services rendered or to come. 